* Corresponding author

E-mail address:san810@gmail.com

Article information

Article history: AMS-Volume16-No. 2-00166-12

Received 4 January 2012

Accepted 15 March 2012

\section{Solid Liquid Non-Newtonian Fluid Flow in Pipe: A Review}

\author{
Mishra S*., Chandra H., Arora. A
}

Bhilai Institute of Technology, Bhilai House, Durg (CG), Pin- 491001

\section{KEY WORDS}

CFD, Non-Newtonian fluid

\section{ABSTRACT}

The flow of rheologically complex fluids in industrial equipment poses a number of challenges, not least from a modeling point of view. Research is needed to further understand and be able to predict the flow behavior of such materials and to investigate ways of improving their processing. The Non-Newtonian Solid-Liquid fluid flow behavior in horizontal and vertical pipes can be predicted by various methods which are mention in the paper. In the literature, it is also shows that Computational Fluid dyanamices (CFD) has sufficient capability to deal with such type of flow and was capable of giving predictions of pressure drop which were probably better and more reliable than the correlations available in the literature.

\section{Introduction}

Multiphase flow of solid-liquid mixtures is encountered in a wide spectrum of industrial processes from the chemical, petrochemical, pharmaceutical, food, and biochemical industries, to mining, construction, pollution control, and power generation. Applications include the hygienic movement and processing of food and pharmaceutical products, the transport of coal and ores, and the secure transportation of effluent and waste products. In such systems, solid-liquid mixtures are conveyed in horizontal or/and vertical pipes.

Solid-liquid flows are usually complex and their behavior is governed by a large number of factors, giving rise to a wide range of flow regimes. Among such factors are flow rate, pipe diameter and orientation, carrier fluid physical and rheological properties, and particle size, density and concentration. There is, therefore, an evident need to classify solid-liquid mixtures in order to provide a rational basis for describing their flow behavior.

Classification of solid-liquid mixtures is a long standing theme in fluid mechanics. In one scheme of classification that recurs frequently in the literature, the behavior of solid-liquid mixtures in horizontal pipes is classified into two categories: settling and non-settling slurries. The settling behavior is usually associated with large solid particles, whereas the non-settling behavior is frequently associated with fine particle suspensions (Brown and Heywood, 1991). However, this classification fails to describe the flow behavior of large neutrally or nearly- neutrally buoyant particle suspensions encountered, for example, in the food industry. Another scheme of classification describes two extremes of slurry behavior based on the physical appearance of the slurry: homogeneous and heterogeneous slurries (Shah and Lord, 1991). This classification provides an indication of the distribution of solid particles over the pipe cross section under flow conditions. Homogeneous mixtures are those in which the distribution of solid particles is uniform over the pipe cross section. Suspensions of fine solid par- 
ticles, where the two phases do not separate to any significant extent during flow, tend to be reasonably homogeneous and are usually treated as such. Although a homogeneous solid-liquid suspension is essentially made up of two distinct phases, there are situations in which particular slurries can be described satisfactorily by single-phase models. Heterogeneous slurry flow, on the other hand, applies to slurries of usually coarse particles where the two phases behave distinctly with a pronounced particle concentration gradient which is a result of particle settling under the influence of gravity. The study of such slurries is therefore more complicated since the single-phase flow approximation is not applicable to such essentially heterogeneous flows.

Although the homogeneous and heterogeneous flow regimes seem distinct, the transition from one regime to the other is not clear cut, and there are flow situations which have some of the characteristics of each regime. For example, food particulates usually have densities close to that of the carrier fluid, resulting in little or no tendency for settling under gravity, a characteristic of homogeneous flows. On the other hand, in the presence of coarse solid particles common in food suspensions, the two phases behave distinctly and the mixture is considered heterogeneous. An intermediate flow has been reported to occur when conditions for homogeneous and heterogeneous flow exist simultaneously (Legrand et al., 2007).

The main distinction between homogeneous and heterogeneous flow lies in the distribution of solid particles in the pipe cross-section. Until recently, no quantitative criterion has been available in the literature to describe particle distribution. The criteria usually used to delineate different flow regimes are generally subjective. Legrand et al. (2007) used a method based on flow visualization in order to characterize food suspensions with quantitative criteria by measuring the cumulative distribution of particles. The authors used large food particles with densities of 1048 and $1116 \mathrm{~kg}$ $\mathrm{m}^{-3}$ at concentrations up to $26 \% \mathrm{w} / \mathrm{w}$.

A major factor which influences the flow behavior of solid-liquid mixtures is the rheological properties of the carrier fluid. In many situations, viscous Newtonian or non-Newtonian fluids are used as the carrier media. These carrier fluids are used because: (a) they are in some cases dictated by the process, e.g. Newtonian heavy oil to transport solids out of wells, and continuous thermal processing of particulate food products in non-Newtonian fluids; and (b) when the flow is laminar, the transport of coarse particles in fluids of non-Newtonian rheology offers certain advantages: (i) the apparent viscosity of a shear thinning fluid is a maximum at the centre of the pipe and this aids particle suspension (though some of this effect may be offset by the propensity of migration across streamlines and the enhanced settling velocities in sheared fluids); (ii) the apparent viscosity is a minimum at the pipe wall, thus, the frictional pressure drop will be low and will increase only relatively slowly with increasing mixture velocity, hence leading to a lower power consumption; and (iii) if the fluid exhibits a yield stress, it tends to assist the suspension of coarse particles in the central region of the pipe (Chhabra and Richardson, 1999).

In practical situations, the transport of particulate matter can occur with a wide size distribution (e.g. coal dust to large lumps); in this case the fine colloidal particles tend to form a pseudo homogeneous shear thinning medium of enhanced apparent viscosity and density in which the coarse particles are conveyed. On the other hand, the heavy medium may consist of fine particles of a different solid, particularly one of higher density such as in the transport of overburden or cuttings in drilling muds. In such cases, the liquid vehicle usually behaves as a Bingham plastic whose yield stress and plastic viscosity increase as the solids concentration increases (Maciejewski et al., 1997). The use (optional or otherwise) of non-Newtonian carrier fluids for processes which involve conveying of slurries through pipes, pipelines, or channels has been restricted by a lack of understanding of the behavior of these flows.

The vast majority of the documented data on solid-liquid flow relate to water-based slurries of fine particles. The flow of particles in non-Newtonian fluids has only been reported in a few studies. Charles and Charles (1971) transported fine sand particles in shear thinning clay suspensions. The head loss was six times smaller compared to that incurred using water as the carrier fluid. Similarly, Ghosh and Shook (1990) reported a reduction in pressure gradient for the flow of fine sand particles in a shear thinning CMC solution, but not for larger pea gravel particles; this was attributed to 
the fact that these larger particles were conveyed in the form of a sliding bed and not as a suspension. Duckworth et al. (1983, and 1986) conveyed coal particles (up to $19 \mathrm{~mm}$ ) in a slurry of fine coal which behaved as a Bingham plastic.

\section{Solid-liquid velocity profiles}

The velocity field of solid particles in a solid-liq- uid mixture determines the residence time distribution of particles, which is of particular relevance to the aseptic processing of solid-liquid food mixtures, where it is essential to ensure that the fastest moving particles receive adequate thermal treatment without causing overcooking and product quality degradation.

\subsection{Causal dependence}

\begin{tabular}{|c|c|c|c|}
\hline Author & Input parameter & Technique used & Conclusion \\
\hline $\begin{array}{l}\text { Newitt et al. } \\
\text { (1962) }\end{array}$ & $\begin{array}{l}\text { Perspex, sand, gravel, and zircon } \\
\text { particles in water }\end{array}$ & Experimental investigation & $\begin{array}{l}\text { The position of the maximum velocity } \\
\text { was not at the pipe centre line but shifted } \\
\text { upwards. The velocity profile of the mixture } \\
\text { below this maximum-velocity point was } \\
\text { found to be parabolic, whereas above this } \\
\text { point it was found to fit a } 1 / 7 \text { th power law } \\
\text { profile. The presence of solid particles redu- } \\
\text { ced the liquid velocity in the pipe centre. }\end{array}$ \\
\hline $\begin{array}{l}\text { Roberts and } \\
\text { Kennedy (1971) }\end{array}$ & $\begin{array}{l}\text { suspensions of neutrally buoyant } \\
\text { cubic and cylindrical solid } \\
\text { particles of } 1015 \text { and } 1052 \mathrm{~kg} \\
\mathrm{~m}^{-3} \text { density, respectively, and } \\
\text { up to } 30 \% \text { solids concentration } \\
\text { in a horizontal pipe of } 50.8 \mathrm{~mm} \\
\text { diameter. }\end{array}$ & $\begin{array}{l}\text { Fluid and particle velocities } \\
\text { were measured using pulsed } \\
\text { injections of salt water and } \\
\text { tagged radioactive particles, } \\
\text { respectively. }\end{array}$ & $\begin{array}{l}\text { Solid particles were found to travel } \\
\text { considerably faster than the mean liquid } \\
\text { velocity, with the difference increasing with } \\
\text { particle concentration. }\end{array}$ \\
\hline $\begin{array}{l}\text { Kowalewski } \\
\text { (1980) }\end{array}$ & $\begin{array}{l}\text { Aqueous suspensions of spheri- } \\
\text { cal particles up to } 50 \% \text { concen- } \\
\text { tration with a density lower than } \\
\text { that of the carrier fluid and for } \\
\text { particle-to-tube diameter ratios } \\
\text { of } 0.001-0.05 \text {. }\end{array}$ & Ultrasound Doppler technique & $\begin{array}{l}\text { The velocity profiles were found to be } \\
\text { blunted and were characterized by a } \\
\text { simple empirical correlation. The degree } \\
\text { of blunting was found to increase with } \\
\text { particle concentration and size. }\end{array}$ \\
\hline $\begin{array}{l}\text { Altobelli et al. } \\
\text { (1991) }\end{array}$ & $\begin{array}{l}\text { The solid particles, which were } \\
\text { made of plastic, had a diameter } \\
\text { of } 0.76 \mathrm{~mm} \text { and density of } 1030 \\
\mathrm{kgm}^{-3} \text {, and the carrier fluid was } \\
\text { Newtonian viscous oil with a } \\
\text { density of } 875 \mathrm{~kg} \mathrm{~m}^{-3} \text {. particle } \\
\text { concentrations up to } 39 \% \mathrm{v} / \mathrm{v} \text {. }\end{array}$ & $\begin{array}{l}\text { Nuclear Magnetic Resonance } \\
\text { (NMR) imaging techniques. } \\
\text { Experiments were conducted } \\
\text { for mean fluid velocities in the } \\
\text { range } 1.7-22.3 \mathrm{~cm} \mathrm{~s}^{-1} \text {. }\end{array}$ & $\begin{array}{l}\text { It was found that for particle concentrati- } \\
\text { ons up to } 10 \% \mathrm{v} / \mathrm{v} \text { the ratio of the centre } \\
\text { line velocity to the mean mixture velocity } \\
\text { exceeded } 2.0, \text { but decreased monotonical- } \\
\text { ly at higher concentrations. }\end{array}$ \\
\hline $\begin{array}{l}\text { Ding et al. } \\
\text { (1993) }\end{array}$ & ---- & $\begin{array}{l}\text { Numerical analysis, using a } \\
\text { computer programme (COM- } \\
\text { MIX M), of the solid-liquid sys- } \\
\text { tems investigated by Altobelli } \\
\text { et al. (1991). }\end{array}$ & $\begin{array}{l}\text { The numerical predictions of the fluid } \\
\text { velocity were inclose agreement with the } \\
\text { experimental data. The authors concluded } \\
\text { that further developments in the multi- } \\
\text { phase solid-liquid model used would lead } \\
\text { to increased confidence in the capability } \\
\text { of the model in simulating dense slurry } \\
\text { flow systems, and that such developments } \\
\text { would result from comparisons with a wide } \\
\text { data base of experimental results. }\end{array}$ \\
\hline Fregert (1995) & $\begin{array}{l}\text { Suspensions of nearly neutrally } \\
\text { buoyant particles in Newto- } \\
\text { nian carrier fluids in a } 45 \mathrm{~mm} \\
\text { diameter pipe. The suspensions } \\
\text { were fairly dilute with particle } \\
\text { concentrations up to } 10 \% \text {, and } \\
\text { the particle to- pipe diameter } \\
\text { ratio ranged from } 0.10 \text { to } 0.16 \text {. }\end{array}$ & Experimental investigation & $\begin{array}{l}\text { Conclude that (i) the maximum particle } \\
\text { velocity occurred } 4-6 \text { mm above the pipe } \\
\text { centre line, (ii) particle velocity was always } \\
\text { smaller than the liquid velocity, and (iii) } \\
\text { liquid velocity was generally slightly higher } \\
\text { than that of the carrier fluid flowing alone. }\end{array}$ \\
\hline
\end{tabular}




\begin{tabular}{|c|c|c|c|}
\hline $\begin{array}{l}\text { McCarthy et al. } \\
\text { (1997) }\end{array}$ & $\begin{array}{l}\text { The pipe had a diameter of } 26.2 \\
\mathrm{~mm} \text {, and the solid particles were } \\
\text { alginate spheres of } 2.5 \mathrm{~mm} \text { and } \\
5.0 \mathrm{~mm} \text { diameters. The particles } \\
\text { were suspended at concen- } \\
\text { trations of } 10 \%, 20 \% \text {, and } 30 \% \\
\mathrm{w} / \mathrm{w} \text { in a } 0.5 \% \mathrm{w} / \mathrm{w} \text { carboxy- } \\
\text { methyl cellulose (CMC) carrier } \\
\text { fluid whose rheology was best } \\
\text { described by a power law model. } \\
\text { The average flow velocity ranged } \\
\text { between } 2-35 \mathrm{~cm} \mathrm{~s}^{-1} \text {. }\end{array}$ & $\begin{array}{l}\text { Nuclear Magnetic Resonance } \\
\text { (NMR) imaging techniques. }\end{array}$ & $\begin{array}{l}\text { The authors described the solid-liquid } \\
\text { suspension with a power law model } \\
\text { by measuring the degree of bluntness } \\
\text { in the solid-liquid velocity profile and } \\
\text { then calculating the corresponding flow } \\
\text { behavior index which would result in the } \\
\text { same degree of bluntness in single-phase } \\
\text { flow. For the CMC solution flowing alone, } \\
\text { the velocity profile, normalized using the } \\
\text { mean flow velocity, showed increased } \\
\text { bluntness as the flow rate was increased. } \\
\text { For solid-liquid suspensions, the bluntness } \\
\text { in the velocity profile was found to increase } \\
\text { with particle concentration. The degree of } \\
\text { bluntness was measured using the ratio of } \\
\text { the flow behavior index of the CMC carrier } \\
\text { fluid flowing alone to that of the solid- } \\
\text { liquid suspension. This ratio was found to } \\
\text { reach } 0.38 \text { at } 30 \% \text { w/w solids. }\end{array}$ \\
\hline $\begin{array}{l}\text { Le Guer et al. } \\
\text { (2003) }\end{array}$ & $\begin{array}{l}\text { Suspensions of buoyant non } \\
\text { spherical particles (few milli- } \\
\text { meters in dimensions) in water, } \\
\text { intended to mimic the flow } \\
\text { behavior of ice water mixtures. } \\
\text { Particle concentrations up to } \\
20 \% \text { w/w were investigated. }\end{array}$ & $\begin{array}{l}\text { Ultrasound Doppler Velocime- } \\
\text { try (UDV) The basic principle } \\
\text { employed in UDV is the me- } \\
\text { asurement of the time lapse } \\
\text { between the transmission of } \\
\text { ultrasonic bursts and recepti- } \\
\text { on of echoes from the flowing } \\
\text { particles, thus allowing the } \\
\text { measurement of the position } \\
\text { of the particles. Flow patterns } \\
\text { were determined by visualiza- } \\
\text { tion of the flow mixture. }\end{array}$ & $\begin{array}{l}\text { Two flow patterns were observed: flow } \\
\text { with a stationary bed at low flow velocities, } \\
\text { with particles rising to the top of the pipe } \\
\text { and forming a stationary bed; and flow } \\
\text { with a moving bed. Due to the formation } \\
\text { of these beds of particles, the velocity } \\
\text { profile of the mixture was found to be } \\
\text { significantly deformed compared with the } \\
\text { velocity profile of water flowing alone. The } \\
\text { deformation of the velocity profile increa- } \\
\text { sed with particle concentration. }\end{array}$ \\
\hline
\end{tabular}

Fairhurst et al. (2001) and Barigou et al. (2003) used the technique of Positron Emission Particle Tracking (PEPT) to determine the trajectories and velocity profile of coarse nearly-neutrally buoyant particles in non-Newtonian CMC carrier fluids. The solid particles used as model food particles were calcium alginate spheres of 5 and $10 \mathrm{~mm}$ diameters and $1020 \mathrm{~kg} \mathrm{~m}^{-3}$ density. Experiments were carried out at particle concentrations of $21 \pm 2 \%$, $30 \pm 2 \%$ and $40 \pm 2 \% \mathrm{v} / \mathrm{v}$ and mixture velocities ranging from 24 to $125 \mathrm{~mm} \mathrm{~s}^{-1}$. The non-Newtonian carrier fluids employed were $0.3 \%, 0.5 \%$, and $0.8 \%$ w/w CMC solutions the rheology of which was characterized by an Ellis model. A gravity-driven flow loop was used wherein the solid-liquid mixture flowed through a down pipe followed by a horizontal pipe, each of $1400 \mathrm{~mm}$ length and 45 $\mathrm{mm}$ inner diameter.

The authors identified two flow situations: concentric flow and capsule flow. The concentric flow pattern, observed at moderately high particle concentrations (e.g. 30\% v/v), was characterized by a slow moving annulus close to the pipe wall and a faster moving central region. In the annular region, the effect of particle settling due to gravity was observed. At the base of the pipe, particles travelled at lower velocities than those at the top of the pipe. Except at the base of the pipe, particles travelled at velocities greater than the mean mixture velocity. At a higher particle concentration $(40 \% \mathrm{v} / \mathrm{v})$, and as particles were confined in a space that was insufficient to accommodate the spatial configuration of concentric flow, particles formed agglomerates, thus leading to capsule flow.

Two types of solid phase velocity profile were measured: global velocity profile and top to bottom velocity profile. The global velocity profile was measured by dividing the pipe cross section into four concentric regions and calculating the mean axial velocity of particles in each region. The top to bottom profile was measured by dividing the pipe cross section into eight sections, four above and four below the pipe centre line, and then calculating the mean velocity in each section as a function of radial position. Global solid phase velocity profiles showed considerable flattening compared with the theoretical single-phase carrier fluid profile and were symmetrical about the pipe centre 
line. Such profiles showed significant deviations from the actual velocities of the solid particles, particularly near the pipe wall, since the global velocity profiles do not take account of the asymmetric flow of the particles due to particle settling. Top to bottom velocity profiles, on the other hand, were found to be generally asymmetrical around the pipe centre line since they do take into account the asymmetric nature of the flow. Such profiles were, therefore, more representative of the actual particle velocities. Particles near the top of the pipe cross-section travelled at axial velocities significantly higher than those at the base of the pipe.

The degree of asymmetry in the top to bottom velocity profile, measured using a 'skewness pa- rameter', was found to depend on the particle size and concentration, mean mixture velocity and carrier fluid viscosity. Asymmetry was strongly evident at the lowest particle concentration used $(21 \% \mathrm{v} / \mathrm{v})$ due to particle settling, with the position of the fastest flowing particles shifted $\sim 2.5 \mathrm{~mm}$ above the centre line; while at higher particle concentrations velocity profiles were more symmetrical as particle settling was limited. The skewness of the solid phase velocity profile for $5 \mathrm{~mm}$ particles was found to be higher than that for $10 \mathrm{~mm}$ particles. It was also found that increasing the apparent viscosity of the carrier fluid reduced the skewness of the solid phase velocity profile.

\subsection{Vertical Flow}

\begin{tabular}{|c|c|c|c|}
\hline Author & & Technique used & Conclusion \\
\hline Durand (1953) & $\begin{array}{l}\text { sand-water mixtures with } \\
\text { particle diameters of } 0.18,1.0 \\
\text { and } 4.6 \mathrm{~mm}\end{array}$ & Experimental investigation & $\begin{array}{l}\text { Presence of solid particles up to } 8 \% \mathrm{v} / \mathrm{v} \text { had } \\
\text { no effect on the velocity profile. }\end{array}$ \\
\hline $\begin{array}{l}\text { Newitt et al. } \\
(1961)\end{array}$ & $\begin{array}{l}\text { Up-flow of suspensions of } \\
\text { sand particles in water up to } \\
15 \% \text { v/v solids. }\end{array}$ & Experimental investigation & $\begin{array}{l}\text { The velocity profile was flat over a large } \\
\text { section of the pipe. As the particle concentra- } \\
\text { tion was increased, the liquid velocity at the } \\
\text { pipe centre decreased and the velocity profile } \\
\text { became flatter with a very steep gradient } \\
\text { near the wall. At high flow velocities, coarse } \\
\text { particles tended to move as a central core } \\
\text { leaving an almost particle-free annulus at the } \\
\text { wall, while at low velocities the distribution } \\
\text { of particles was fairly uniform across the pipe } \\
\text { cross-section. }\end{array}$ \\
\hline $\begin{array}{l}\text { Sinton and } \\
\text { Chow (1991) }\end{array}$ & $\begin{array}{l}\text { Poiseuille Newtonian flow- The } \\
\text { particles had a median dia- } \\
\text { meter of } 0.131 \mathrm{~mm} \text { and were } \\
\text { suspended at concentrations } \\
\text { of } 21-52 \% \mathrm{~V} / \mathrm{V} \text {. }\end{array}$ & $\begin{array}{l}\text { Nuclear Magnetic Resonance } \\
\text { (NMR) imaging techniques. }\end{array}$ & $\begin{array}{l}\text { The shape of the fluid velocity profile chan- } \\
\text { ged with particle concentration. The velocity } \\
\text { profile was parabolic at low concentrations } \\
\text { and flattened at higher concentrations. }\end{array}$ \\
\hline $\begin{array}{l}\text { Ding et al. } \\
\text { (1993) }\end{array}$ & 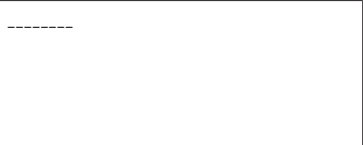 & $\begin{array}{l}\text { The computer code COM- } \\
\text { MIX-M }\end{array}$ & $\begin{array}{l}\text { Compute fluid velocities for the same solid-li- } \\
\text { quid systems for which the experimental data } \\
\text { of Sinton and Chow (1991) were obtained } \\
\text { and reasonable agreement was found. }\end{array}$ \\
\hline $\begin{array}{l}\text { Alajbegovic et } \\
\text { al. (1994) }\end{array}$ & $\begin{array}{l}\text { Dilute aqueous suspensions } \\
\text { of non-neutrally buoyant } \\
\text { particles of } 2 \mathrm{~mm} \text { diameter in } \\
\text { vertical up-flow. }\end{array}$ & Laser-Doppler anemometer & $\begin{array}{l}\text { Particles denser than the carrier fluid lagged } \\
\text { the fluid close to the pipe centre line, but tho- } \\
\text { se flowing near the pipe wall were faster than } \\
\text { the fluid. On the other hand, particles less } \\
\text { dense than the carrier fluid travelled faster } \\
\text { than the fluid at all radial positions. It was also } \\
\text { observed that the dense particles showed } \\
\text { a uniform distribution across the pipe cross } \\
\text { section at low flow rates, while coring was } \\
\text { observed at higher flow rates where a region } \\
\text { near the pipe wall was observed to contain } \\
\text { almost no particles. For the less dense partic- } \\
\text { les, however, the distribution profile showed a } \\
\text { maximum close to the pipe wall for low flow } \\
\text { rates which flattened at higher flow rates. }\end{array}$ \\
\hline
\end{tabular}




\begin{tabular}{|c|c|c|c|}
\hline $\begin{array}{l}\text { Lareo et al. } \\
\text { (1997(b) and } \\
1997(c))\end{array}$ & $\begin{array}{l}\text { Solid-liquid food mixtures } \\
\text { flowing upwards in a } 44 \\
\text { mm diameter pipe. Particle } \\
\text { concentrations up to only } \\
10 \% \text { w/v were used since at } \\
\text { higher concentrations the } \\
\text { tracer could not be reliably } \\
\text { seen among the large number } \\
\text { of particles in the pipe. The } \\
\text { food particles used were } \\
\text { cubed carrots with edge sizes } \\
\text { within } 6-10 \text { mm and densities } \\
\text { ranging mainly between } 1016- \\
1030 \mathrm{~kg} \mathrm{~m} \mathrm{~m}^{-3} \text {. The carrier fluids } \\
\text { were } 0.3 \% \text { and } 0.8 \% \text { w/w CMC } \\
\text { solutions (non-Newtonian). }\end{array}$ & $\begin{array}{l}\text { Video recording technique } \\
\text { was used to determine the } \\
\text { position and axial velocity of } \\
\text { tracer particles, thus allowing } \\
\text { the calculation of velocity and } \\
\text { distribution profiles of the } \\
\text { particles. }\end{array}$ & $\begin{array}{l}\text { As the particle concentration was increased, } \\
\text { (i) the number of particles flowing in the } \\
\text { central region of the pipe increased, (ii) the } \\
\text { velocity profile of particles became flat near } \\
\text { the pipe centre line, and (iii) some particles } \\
\text { were seen to flow close to the wall. }\end{array}$ \\
\hline $\begin{array}{l}\text { Fairhurst et al. } \\
\text { (2001) }\end{array}$ & $\begin{array}{l}\text { The solid particles had a dia- } \\
\text { meter of } 10 \mathrm{~mm} \text { and a density } \\
\text { of } 1020 \mathrm{~kg} \mathrm{~m}^{-3} \text { and were sus- } \\
\text { pended at } 21 \%, 30 \% \text { and } 40 \% \\
\text { v/v concentrations in } 0.5 \% \text { and } \\
0.8 \% \text { w/w CMC solutions, at } \\
\text { mean mixture velocities in the } \\
\text { range } 65-125 \mathrm{~mm} \mathrm{~s}^{-1} \text {. }\end{array}$ & $\begin{array}{l}\text { Positron Emission Particle } \\
\text { Tracking (PEPT) }\end{array}$ & $\begin{array}{l}\text { The solid phase velocity profile was found to } \\
\text { be symmetrical due to the absence of gravi- } \\
\text { tational effects in vertical flow. The velocity } \\
\text { profile was more flattened than that obtained } \\
\text { under the same conditions in horizontal flow. }\end{array}$ \\
\hline
\end{tabular}

\section{Solid-liquid pressure drop}

Pressure drop in multiphase solid-liquid flow remains one of the most difficult parameters to predict. Solid-liquid pressure drop depends on the flow regime, which in turn is dictated by the complex interaction of many variables (e.g. particle diameter, concentration and density, flow velocity and fluid viscosity). It is well established that the presence of solid particles in a carrier fluid gives rise to an increase in the pressure drop incurred, but there are no theoretical models available for calculating such a pressure drop. However, many empirical and semi-empirical approaches do exist. Due to the strong dependence of pressure drop on the flow conditions, empirical correlations tend to be specific, not only to the flow regime for which they were developed, but also to the conditions under which the experimental data used in their derivation were obtained. Any attempt to use such correlations to predict pressure drop under other conditions is likely to lead to significant errors (Crowe et al., 1998).

The classical empirical correlation of Durand and Condolios (Durand and Condolios, 1952), which stands as a reference in the field of slurry flow, was developed using data for highly turbulent sand and gravel slurries with particle diameters in the range $0.2-25 \mathrm{~mm}$, solid concentrations up to $60 \%$ $\mathrm{v} / \mathrm{V}$, and pipe diameters of 38-580 $\mathrm{mm}$. Durand and Condolios found that their results were indepen- dent of particle diameter for particles larger than $20 \mathrm{~mm}$ in diameter. They therefore looked for a parameter which would be largely dependent on particle size for small particles but less so for larger ones and chose the drag coefficient on a particle at its terminal velocity. The correlation obtained contains two empirical constants. A wide range of different values of one of these constants can be found in the literature which serves to caution against the indiscriminate use of empirical methods outside the range of variables for which they were derived.

A number of authors reported that the DurandCondolios correlation, while representing a milestone in the field, has limited applicability. For example, Rasteiro et al. (1993) commented that this correlation may produce deviations of up to 55\% from measured values. Turian et al. (1971) also reported deviations exceeding 50\%. Darby (1986), on the other hand, indicated that Durand-Condolios' correlation does not account for inter-particle interactions. Babcock (1971), who carried out a systematic series of experiments designed to asses the role of each of the groups in Durand-Condolios' correlation, argued that the dimensionless groups in the correlation are not sufficient to account for the influences of particle size and concentration and pipe diameter.

Zandi and Govatos (1967) proposed a modified version of Durand-Condolios' equation to correlate 
approximately 1000 data points collected from various sources. However, their correlation has been hampered by the exclusion of a large set of data points and the arbitrary transition criterion used to demarcate between flow regimes (Turian and Yuan, 1977).

Turian and Yuan (1977) noted the importance of ordering experimental data relating to slurry pressure drop according to flow regimes, since it allows the classification of data into groupings of more manageable size compared to the vast number and range of variables influencing the flow. The authors proposed a set of four equations for the estimation of pressure drop for four different flow regimes: homogeneous flow, heterogeneous flow, saltation flow, and flow with a stationary bed. They used another set of equations to delineate the four flow regimes. The authors used a vast number of data points obtained from both the literature and their own work in arriving at these correlations. Apart from the complexity of the correlations, Shook and Roco (1991) showed that the prediction of pressure drop using these correlations may sometimes deviate considerably from actual values, even under conditions that are entirely within the range of data used in deriving the correlations, and that the problem is not one of regime definition.

Chhabra and Richardson (1985) presented a correlation for the prediction of the hydraulic pressure gradient based on experimental data relating to mixtures with a sliding bed. They concluded from a review of the literature that there were then insufficient reliable results for expressions to be given for the pressure gradients in other flow regimes.

Khan et al. (1987) discussed the works of principal investigators, including those of Durand and Condolios (1952) and Chhabra and Richardson (1985), and drew attention to some of the drawbacks of such correlations and the very wide discrepancies between the results of different researchers even when obtained under nominally similar conditions. They argued that, in these works, no account was taken of the substantial effect of particle concentration on drag, and that the particle concentration used was that measured in the discharged mixture which will, in general, be lower than that measured in situ which determines the nature of the flow. The authors, therefore, developed experimental techniques for measuring the in-pipe particle con- centration and fluid velocity using $\mathrm{\gamma}$-ray absorption and salt injection, respectively.

As can be seen, a purely experimental approach to the problem of pressure drop prediction in solid-liquid mixtures is faced by difficult constraints arising from (i) the abundance of the variables influencing the flow which makes the variety of solid-liquid systems almost unlimited, (ii) the wide range over which these variables may vary, and (iii) the limitations on accuracy and reproducibility of data (Turian et al., 1971). Due to these difficulties, emphasis has more recently shifted to modeling of solid-liquid flows. As also noted by Shook and Roco (1991), as the data base for solid-liquid flow continues to grow, the importance of experimental correlations will gradually diminish compared to mechanistic models.

Rasteiro et al. (1993) derived a semi-theoretical correlation for the prediction of pressure drop in heterogeneous solid-liquid mixtures in turbulent flow. The authors first computed the concentration profile of solid particles in the pipe cross-section and then used it to calculate the pressure drop. The model adopted to describe the flow of suspensions states that the suspension of solid particles is a result of a dynamic equilibrium between the tendency of the particles to settle due to gravity and their tendency to disperse due to turbulence. By solving the model equations, the particle distribution was obtained. The pipe cross-section was divided into slices of nearly constant concentration and pressure drop was evaluated for each slice using the proposed correlation. The total pressure drop was then obtained by integrating these local pressure drops. The empirical constants in the correlation were determined using experimental data for solid particles of high density (up to $2650 \mathrm{~kg}$ $\mathrm{m}^{-3}$ ) ranging in size from 0.16 to $1.28 \mathrm{~mm}$ in highly turbulent flow with velocities in the range 0.98$3.76 \mathrm{~m} \mathrm{~s}^{-1}$. Particle concentration varied from $2 \%$ to $34 \% \mathrm{v} / \mathrm{v}$.

The model was found to give improved pressure drop predictions compared to Durand Condolios' correlation. Deviations from experimental data of less than 29\% were obtained over the broad range of operating conditions considered, whereas Durand-Condolios' equation produced deviations up to $55 \%$ from the same experimental data.

Doron and Barnea (1993) developed a three layer model for the calculation of pressure drop 
which treats the flow of settling mixtures as being constituted of three layers: a stationary layer at the base of the pipe, a moving bed layer above it, and a heterogeneous suspension layer in the rest of the pipe. In a later study, Doron and Barnea (1995) compared new experimental data, obtained using particles of $3 \mathrm{~mm}$ diameter and 1240 $\mathrm{kg} \mathrm{m}^{-3}$ density in water, to the predictions of the three layer model. The comparison showed satisfactory agreement. The pressure drop was found to increase with particle concentration. It should be noted that such models, usually applicable to heavy particles in turbulent flows, are not appropriate for estimating pressure drop in solid-liquid food suspensions where the densities of the two phases are similar and the objective of the flow is to avoid particle settling rather than to model the sedimentation layers.

For fine particles which give rise to homogeneous or near homogeneous suspensions, the suspension can be treated as a continuum and calculation of pressure drop can be based on the bulk properties of the suspension (Khan et al., 1987). This continuum approach may also be applied to dilute coarse particle suspensions where the solid-liquid suspension can be approximated as a single phase fluid with properties equivalent to the mean properties of the suspension. This approximation allows the calculation of pressure drop as a function of the suspension Reynolds number in the same way as in single-phase flows. This approach was used by Gradeck et al. (2005) to calculate the pressure drop of fairly dilute solid-liquid suspensions with coarse $(\mathrm{d}=4.4 \mathrm{~mm}$ ) nearly-neutrally buoyant alginate particles in water and glucose solutions (Newtonian) and CMC solutions (non-Newtonian) in a $30 \mathrm{~mm}$ diameter pipe. This method does not account for particle-particle interactions, which increase in significance with particle concentration, and is therefore inapplicable in concentrated suspensions.

\section{Multiphase Solid-liquid CFD}

Computational fluid dynamics (CFD) has been a powerful tool in modeling multiphase flows. Despite the current capabilities of CFD in investigating complex multiphase flows, experimental data are still needed for the development of any numerical or computational model. As frequently noted in the literature, there is a lack of experimental data in many multiphase areas, particularly solid-liquid flows. Moreover, such data, when available, tend to be specific and apply only for the conditions under which they were obtained

The use of CFD in modeling multiphase solid-liquid flow has been notably limited. As noted by Van Wachem and Almstedt (2003), this is due to three factors: (i) the inherent complexity of the physical phenomenon of multiphase flow, reflected in the wide range of flow types and regimes encountered in such flows; (ii) the complex mathematical treatment of such flows remains still undeveloped; and (iii) the numerics required to solve multiphase governing equations are extremely complex.

Nevertheless, substantial effort has been directed at the development of CFD models for multiphase systems, and the application of these models in industry has been growing steadily. In fact, CFD models have reached such complex levels in their treatment of multiphase flows that they sometimes outstrip the ability to obtain experimental data with which to evaluate them (Kleinstreuer, 2003). Kleinstreuer (2003) discussed the capabilities of different CFD software packages in modeling a range of multiphase flows and presented several cases of the application of CFD in the study of complex biomedical engineering-related multiphase flows drawn from the results of the author's group of research. CFD models were constructed using the commercial code CFX 4.4 and validated using available experimental data.

Van Wachem and Almstedt (2003) presented an overview of the CFD models used for multiphase flows. The authors derived the governing equations and closure models for multiphase flow and presented and compared different methods and formulations used for modeling such flows. It was concluded that the application of CFD in studying multiphase flow is promising but nonetheless requires further development.

There are two numerical approaches used to model multiphase flows: the Eulerian- Eulerian and Eulerian-Lagrangian methods. The Eulerian-Eulerian method, also known as the two-fluid method, regards the dispersed phase as a continuous phase, i.e. as a fluid. This method accounts more easily for particle-particle interactions and is widely used for mixtures with high particle concentrations. Multiphase flow models within this method can be subdivided into two categories: homogeneous and inhomogeneous. The homogeneous flow model 
views the mixture as one fluid with the bulk properties modified to account for the presence of the solid particles. The inhomogeneous flow model, on the other hand, views the two phases as distinct, interacting continua.

Since the dispersed solid phase is treated as a continuum in the Eulerian-Eulerian approach, an effective viscosity has to be assigned to this phase. This imposes a conceptual difficulty since viscosity is a property of continuous fluids only. However, as discussed above, the literature contains a number of expressions for the calculation of suspension viscosity which can then be used to calculate a hypothetical solid phase viscosity. These expressions have been shown to represent the rheological behavior of food suspensions satisfactorily (Chakrabandhu and Singh, 2005).

With the rapid increase of computational power, the particle tracking Eulerian-Lagrangian approach has become feasible. This approach calculates the trajectories of particles in the flow. This method is computationally expensive and valid only for very dilute mixtures, i.e. $<\sim 2 \% \mathrm{v} / \mathrm{v}$ (Van Wachem and Almstedt, 2003).

The success of any of these modeling methods depends on the accurate modeling and appropriate inclusion in the governing and closure equations of the various complex effects that occur in multiphase flows. This, however, requires a solid understanding of the fundamentals of multiphase flows. Numerical modeling and experimental approaches are complementary of each other, since experimental data are indispensable for the development and validation of numerical models while numerical models can provide more comprehensive data than experiment.

Norton and Sun (2006) conducted a state-of-theart review of the applications of CFD in the food industry, including food sterilisation. A steady increase has been observed in the number of studies relating to CFD applications in the food industry. For example, CFD has helped overcome some of the difficulties in relating heat transfer in food products to sterility and quality levels. CFD can assist the understanding of the physical mechanisms that govern the various properties of food products, including solid-liquid mixtures.

Smith et al. (2000) conducted a CFD study of solid-liquid mixing in a tank using the commercial software CFX 4.2. The system consisted of a sta- tionary liquid into which neutrally-buoyant solid particles $6.25 \mathrm{~mm}$ in diameter were dropped. The model was validated by comparing its predictions with experimental results obtained by the authors, and good agreement was found. The model was then extended to study the dispersion of solid particles in a horizontal channel flow. This study was intended as a first step towards simulating the dispersion of solid particles falling into a flowing melt.

Krampa-Morlu et al. (2004) used CFD to predict the flow features of aqueous solid-liquid slurries in turbulent upward pipe flow. Among the investigated features was the velocity profile. Particles had a density of $2650 \mathrm{~kg} \mathrm{~m}^{-3}$ and diameter of 0.47 or $1.7 \mathrm{~mm}$ at concentrations up to $30 \% \mathrm{v} / \mathrm{v}$. The CFD model, formulated using the software CFX 4.4, was tested using the experimental results of Sumner et al. (1990). The agreement between CFD and experiment was generally good for the smaller particles but deteriorated for the $1.7 \mathrm{~mm}$ diameter particles. The authors concluded that the code failed to accurately predict important features of the flow using the default settings.

An example of the successful application of CFD in modeling solid-liquid food mixtures is the work of Abdul Ghani and Farid (2007) who used CFD to predict the temperature distribution and velocity and pressure profiles during high pressure compression of solid-liquid (beef-water) food mixtures within a $38 \mathrm{~mm}$ diameter cylinder. The CFD model, constructed using the commercial finite-volume code PHOENICS 3.5, was validated using experimental data reported in the literature, and a very close agreement was obtained. The CFD results showed for the first time the effect of forced convection heat transfer on the temperature distribution of the solid and liquid phases. The temperature distribution at different stages of the high pressure process was obtained.

Eesa, M. \& Barigou, M. (2008. \& 2009) was numerically simulated the horizontal flow of course particle suspensions in non-Newtonian carrier fluids using an Eulerian-Eulerian numerical model. The CFD computations of solid phase velocity profile and particle passage times matched the experimental PEPT and Hall Effect sensors measurements to a very good degree of accuracy. CFD study shows that, except for the smaller particles $(<4 \mathrm{~mm})$, the velocity profile of the solid phase exhibited a significant degree of asymmetry which 
increased with particle size due to the increased propensity of particle settling. Also, with increasing particle size $(\mathrm{d}>4 \mathrm{~mm})$, the maximum solids velocity decreased and the position at which this velocity occurred shifted upwards above the centre line. Particles generally travelled faster than the mean mixture velocity, and while the maximum particle velocity was considerably less than twice the mean mixture velocity in shear-thinning carrier fluids, it exceeded this value in strongly shear thickening fluids $(\sim n>1.75)$. Larger particles also caused significant blunting and asymmetry in the liquid phase velocity profile. Whereas the particle concentration profile was nearly uniform for smaller particles $(\mathrm{d}<3 \mathrm{~mm})$, indicating a pseudo-homogeneous flow, increasing the particle diameter distorted the concentration profile due to enhanced settling. The solid-liquid pressure drop declined as particle diameter increased.

Eesa, M. \& Barigou, M. (2008. \& 2009) concluded that, at higher solid concentrations, the solid phase and liquid phase velocity profiles became flatter and the particles were radially more uniformly distributed. Increasing the concentration also increased the pressure drop incurred considerably as the friction losses due to particle interactions increased. Increasing the mean flow velocity had no influence on the normalized velocity profile of phase, the normalized particle concentration profile, or the pressure drop increase relative to the carrier fluid flowing alone. The fluid consistency index did not have any influence on the normalized velocity profiles, normalized particle distribution, or pressure drop increase relative to single phase flow. However, more shear thinning, i.e. lower n, induced a gradual flattening of the velocity profile of the solid phase and of the liquid phase relative to the fluid flowing alone. No significant effects were observed on the normalized particle concentration profile or the increase in pressure drop compared to single phase flow.

In vertical down-flow, particle radial distribution was remarkably uniform under all conditions investigated. The normalized solid-phase and liquid-phase velocity profiles and normalized particle concentration profile were independent of particle size and concentration under the conditions studied. However, increasing particle concentration resulted in a significant rise in pressure drop relative to single phase flow. These results have important practical implications for the processing of solidliquid food mixtures where knowledge of the solid phase and liquid phase velocity profiles is crucial for the design of the process. The Eulerian approximation of the solid phase has thus been shown to be useful in predicting the behavior of such systems.

\section{Conclusion}

A vast range of fluids of complex structures are now used in manufacturing an increasing number of products in a wide spectrum of industries including food, polymer, pharmaceutical, and chemical industries, in addition to applications in the oil, mining, construction, water treatment and power generation industries. Non-Newtonian fluids have received significant attention from researchers over the past decades due to their increasing importance in industry. This is reflected in the growing volume of research dealing with the structure, properties and flow behaviour of such fluids. Nonetheless, this area of research is vast and growing, and further studies into the behaviour of non-Newtonian fluids in complex flow situations are still needed.

A number of experimental techniques have been used in studying non-Newtonian flows, such as Laser Doppler Velocimetry (LDV), Particle Imaging Velocimetry (PIV), Nuclear Magnetic Resonance Imaging (NMR) and Positron Emission Particle Tracking (PEPT), but its application in this area has so far been limited.

While the measurement of solid and liquid phase velocity profiles in industrial solid-liquid mixtures is usually difficult. Computational Fluid Dynamics (CFD) is a useful tool for studying non-Newtonian flows. The CFD-predicted solid-phase velocity profiles were successfully validated using experimental PEPT measurements, whilst the computed solid-liquid pressure drop was validated using correlations from the literature (Eesa, M. \& Barigou, M., 2009).

Whilst a thorough validation of CFD would require more extensive experimental data on pressure drop, which are presently unavailable in the literature, the study conducted by Eesa, M. \& Barigou, M. (2009) has shown that, overall, CFD is capable of giving predictions which are no worse but probably more reliable than the correlations available in the literature as it is based on a full solution 
of the flow field. In this paper, it is shown that CFD have lot of potential to deal with non-newtonian fluid flow behaviour and pressure drop during the flow is concern.

\section{References}

Abdul Ghani, A.G. \& Farid, M.M. 2007. Numerical simulation of solid-liquid food mixture in a high pressure processing unit using computational fluid dynamics. J. Food Eng., 80 (4), 10311042

Alajbegovic, A., Asad, A., Bonetto, F. \& Lahey Jr., R.T. 1994. Phase distribution and turbulence structure for solid/liquid upflow in a pipe. Int. J. Multiphase Flow, 20 (3), 453-479.

Altobelli, S.A., Givler, R.C. \& Fukushima, E. 1991. Velocity and concentration measurements of suspensions by nuclear magnetic resonance imaging. J. Rheol, 35 (5), 721-734.

Babcock, H.A. 1971. Heterogeneous flow of heterogeneous solids. In: Advances in solid-liquid flow in pipes and its application. Zandi, I. (Editor), Pergamon Press, N.Y.

Barigou, M., Fairhurst, P. G., Fryer, P.J. \& Pain, J.-P. 2003. Concentric flow regime of solid liquid food suspensions: theory and experiment. Chemical Engineering Science, 58, 1671-1686.

Brown, N.P. \& Heywood, N.I. 1991. Slurry handling: design of solidliquid systems. Elsevier Science Publishing LTD.

Chakrabandhu, K. \& Singh, R.K. 2005. Rheological properties of coarse food suspensions in tube flow at high temperatures. Journal of Food Engineering, 66, 117- 128.

Charles, M.E. \& Charles, R.A. 1971. In: Advances in solid-liquid flow and its applications. Zandi, I. (Editor), Pergamon.

Chhabra, R.P. \& Richardson, J.F. 1999. Non-Newtonian flow in the process industries: Fundamentals and engineering applications. Butterworth Heinemann.

Chhabra, R.P. \& Richardson, J.F. 1985. Hydraulic transport of coarse particles in viscous Newtonian and non-Newtonian media in a horizontal pipe. Chem Eng Res Des, 63, 390-397.

Crowe, C.T., Sommerfeld, M. \& Tsuji, Y. 1998. Multiphase flows with droplets and particles. CRC Press LLC.

Darby, R., 1986. Encyclopedia of Fluid Mechanics. Vol 5, Slurry flow technology. Cheremisinoff, N.P. (Editor). Gulf Publishing Company, Houston, Texas.

Ding, J., Lyczkiwski, R.W., Sha, W.T., Altobelli, S.A. \& Fukushima, E. 1993. Numerical analysis of liquid-solids suspension velocities and concentrations obtained by NMR imaging. Powder Technology, 77, 301-312.

Doron, P. \& Barnea, D. 1995. Pressure drop and limit deposit velocity for solid-liquid flow in pipes. Chemical Engineering Science, 50 (10), 1595-1604.

Doron, P. \& Barnea, D. 1993. A three-layer model for solid-liquid flow in horizontal pipes. Int. J. Multiphase Flow, 19, 10291043.
Duckworth, R.A., Pullum, L. \& Lockyear, C.F. 1983. The hydraulic transport of coarse coal at high concentration. J. Pipelines, 3, 251-65.

Duckworth, R.A., Pullum, L., Addie, G.R. \& Lockyear, C.F. 1986. Pipeline transport of coarse materials in a non-Newtonian carrier fluid. Hydrotransport 10, Paper C2, 69- 88.

Durand R. 1953. Basic relationship of the transportation of solids in pipes experimental research. Proc. of Minnesota Int. Hydraulic Convention. Minneapolis, MN, 89-103.

Durand, R. \& Condolios, E. 1952. Experimental study of the hydraulic transport of coal and solid materials in pipes. Proc. Colloq. on the hydraulic transport of coal. National Coal Board, London, UK, Paper IV, 39-55. [Cited in: Shook and Roco, 1991]

Eesa, M. \& Barigou, M. 2008. Horizontal laminar flow of coarse nearly-neutrally buoyant particles in non-Newtonian conveying fluids: CFD and PEPT experiments compared. Int. J. Multiphase Flow, 34, 997-1007.

Eesa, M. \& Barigou, M. 2009. CFD investigation of the pipe transport of coarse solids in laminar power law fluids. Chemical Engineering Science, 64, 322-333.

Fairhurst, P.G., Barigou, M., Fryer, P.J., Pain, J-P. \& Parker, D.J. 2001. Using positron emission particle tracking (PEPT) to study nearly neutrally buoyant particles in high solid fraction pipe flow. Int. Journal of Multiphase Flow, 27, 1881-1901.

Fregert, J. 1995. Velocity and concentration profiles for a laminar flow for a fluid containing large spheres in a horizontal pipe. Ph.D thesis, Lund University, Sweden.

Ghosh, T. \& Shook, C.A. 1990. In: Freight pipelines, H. Liu and G.F. Round (Editors), Hemisphere.

Gradeck, M., Fagla, B.F.Z., Baravian, C. \& Lebouché, M. 2005. Technical Note: Experimental thermomechanic study of Newtonian and non-Newtonian suspension flows. Int. Journal of Heat and Mass Transfer, 48, 3769-3477.

Khan, A.R. \& Richardson, J.F. 1987. The resistance to motion of a solid sphere in a fluid. Chem. Eng. Commun., 62, 135-150.

Kleinstreuer, C. 2003. Two-phase flow: theory and applications. Taylor \& Francis Books, Inc.

Kowalewski, T.A. 1980. Velocity profiles of suspension flowing through a tube. Arch Mech, 32 (6), 857-865.

Krampa-Morlu, F.N., Bergstrom, D.J., Bugg, J.D., Sanders, R.S. \& Schaan, J. 2004. Numerical Simulation of dense coarse particle slurry flows in a vertical pipe. 5th International Conference on Multiphase Flow, ICMF'04, paper No.460.

Lareo, C., Nedderman, R.M. \& Fryer, P.J. 1997(c). Particle velocity profiles for solid liquid food flows in vertical pipes, Part II: multiple particles. Powder Technology, 93, 35-45.

Legrand, A., Berthou, M. \& Fillaudeau, L. 2007. Characterization of solid-liquid suspensions (real, large non-spherical particles in non-Newtonian carrier fluid) flowing in horizontal and 
vertical pipes. Journal of Food Engineering, 78, 345-355

Le Guer, Y., Reghem, P., Petit, I. \& Stutz, B. 2003. Experimental study of a buoyant particle dispersion in pipe flow. Trans IChemE, 81, Part A, 1136-1143.

Maciejewski, W., Lord, E., Gillies, R. \& Shook, C. 1997. Pipeline transport of large ablating particles in a non-Newtonian carrier. Powder Technology, 94, 223-228.

McCarthy, K.L, Kerr, W.L. \& Kauten, R.J. 1997. Velocity profiles of fluid/particulate mixtures in pipe flow using MRI. J. Food Process. Eng, 20, 165-177.

Newitt, D.M., Richardson, J.F. \& Gliddon, J.F. 1961. Hydraulic conveying of solids in vertical pipes. Trans. Instn. Chem. Eng., 39, 93-100.

Newitt, D.M., Richardson, J.F. \& Shook, C.A. 1962. Hydraulic conveying of solids in horizontal pipes. Part II: Distribution of particles and slip velocities. In: Proceedings: Interaction between fluids and particles, IChemE, London, 87-100.

Norton, T. \& Sun, D.W. 2006. Computational fluid dynamics (CFD) an effective and efficient design and analysis tool for the food industry: A review. Trends in Food Science \& Technology, 17, 600-620.

Rasteiro M.G., Figueiredo M.M. \& Franco H. 1993. Pressure drop for solid/liquid flow in pipes. Particulate Science and Technology, 11, No. 3-4: 147-155.

Roberts, C.P.R. \& Kennedy, J.F. 1971. Particle and fluid velocities of turbulent flows of suspensions of neutrally buoyant particles. In Advances in Solid-Liquid Flow in Pipes and Its Appli- cations. Zandi, I. (Editor), 59-72. Pergamon Press, Oxford, UK. Shah, S.N. \& Lord, D.L. 1991. Critical velocity correlations for slurry transport with non-Newtonian fluids. AIChE J., 37 (6), 863870.

Shook, C.A. \& Roco, M.C. 1991. Slurry flow: principles and practice. Butterworth- Heimemann.

Sinton, S.W. \& Chow, A.W. 1991. NMR flow imaging of fluids and solid suspensions in Poiseuille flow. J. Rheol, 35 (5), 735-771.

Smith, K.M., Davidson, M.R \& Lawson, N.J. 2000. Dispersion of neutrally buoyant solids falling vertically into stationary liquid and horizontal channel flow. Computers \& Fluids, 29, 369384.

Sumner, R.J., McKibben, M.J. \& Shook, C.A. 1990. Concentration and velocity distributions in turbulent vertical slurry flows. Ecoulements Solide-Liquide, 2 (2): 33-42

Turian, R.M. \& Yuan, T.F. 1977. Flow of Slurries in Pipelines. AIChE J., 23 (3), 232- 243.

Turian, R.M., Yuan, T.F. \& Giacomo, M. 1971. Pressure drop correlation for pipeline flow of solid-liquid suspensions. AlChE J., 17, No. 4, 809-817.

Van Wachem, B.G.M. \& Almstedt, A.E. 2003. Methods for multiphase computational fluid dynamics. Chemical Engineering Journal, 96, 81-98.

Zandi, I. \& Govatos, G. 1967. Heterogeneous flow of solids in pipelines. Journal of Hydraulics Division, Proceedings of the American Society of Civil Engineers, May, 93 (HY3): 145-159 